\section{ESTADO NUTRICIONAL E PREVALÊNCIA DE ANEMIA EM CRIANÇAS MENORES DE 36 MESES}

\author{
Nutritional status and prevalence of anemia in children under \\ 36 months
}
Estado nutricional y prevalencia de anemia en niños menores de 36 meses

\section{RESUMO}

Objetivos: Estimar a prevalência de anemia correlacionando com o estado nutricional de crianças menores de 36 meses. Métodos: Estudo observacional, transversal, retrospectivo e analítico, realizado com 374 crianças com idade inferior a 36 meses, de creches municipais de Vitória, ES. Foi realizada antropometria e coletadas amostras de sangue para dosagem de hemoglobina $(\mathrm{Hb})$, ferro sérico (FeS) e ferritina sérica (FS). Para análise estatística utilizou-se o teste qui-quadrado e o teste exato de Fisher. Resultados: A prevalência de anemia nos préescolares foi de 10,9\% $(\mathrm{n}=19)$. Níveis inadequados de ferritina estiveram presentes em 7,5\% $(n=13)$ das crianças e de ferro sérico em 27,6\% $(n=48)$. O estado nutricional da criança não mostrou associação estatisticamente significante com a anemia. Conclusão: A prevalência de anemia na população estudada caracteriza um problema leve de saúde pública, não sendo observada associação do estado nutricional a essa deficiência.

Descritores: Anemia Ferropriva; Estado Nutricional; Saúde da Criança.

\section{ABSTRACT}

Objective: To estimate the prevalence of anemia associated with nutritional status in children under 36 months of age. Methods: This is an observational, cross-sectional, analytical study conducted in 2007 comprising 374 children under 36 months of age enrolled at a municipal day care center. Anthropometric assessment and blood sample collection were performed, being measured Hemoglobin (Hb), serum iron (SFe) and serum ferritin (SF). For statistical analysis, chi-square and Fisher's exact test were used. Results: The prevalence of anemia among preschool children was of $10.9 \%(n=19)$. Inadequate levels of serum ferritin and serum iron were present in $7.5 \%(n=13)$ and $27.6 \%(n=48)$ of the children, respectively. The children's nutritional status showed no statistically significant association with anemia. Conclusion: The prevalence of anemia in the studied population features a mild public health problem, without association with the nutritional status.

Descriptors: Anemia; Iron Deficiency; Nutritional Status; Child Health.

\section{RESUMEN}

Objetivo: Estimar la prevalencia de anemia y correlacionar con el estado nutricional de niños menores de 36 meses. Métodos: Estudio observacional, trasversal, retrospectivo y analítico realizado con 374 niños abajo de 36 meses, de guarderías municipales de Vitória, ES. Se realizó antropometría y fueron recogidas muestras de sangre para la dosificación de hemoglobina (Hb), hierro sérico (HS) y ferritina sérica (FS). Para el análisis estadístico se utilizó las pruebas de chi-cuadrado y el exacto de Fisher. Resultados: La prevalencia de anemia en los pre-escolares fue del 10,9\% $(n=19)$. Niveles inadecuados de ferritina estuvieron presentes en el 7,5\% $(n=13)$ de los niños y de hierro sérico en el 27,6\% $(n=48)$. El estado nutricional del niño no mostró asociación estadísticamente significativa con la anemia. Conclusión: La prevalencia de anemia en la población estudiada se caracteriza un problema leve de salud pública, no siendo observada la asociación del estado nutricional y esa deficiencia.

Descriptores: Anemia Ferropénica; Estado Nutricional; Salud del Niño.
Artigo Original
1) Universidade Federal do Espírito Santo Vitória (ES) - Brasil

2) Hospital Infantil Nossa Senhora da Glória - Vitória (ES) - Brasil

3) Faculdade Estácio de Sá de Vitória FESV - Vitória (ES) - Brasil
Recebido em: 04/03/2013

Revisado em: 09/05/2013 Aceito em: 12/09/2013 


\section{INTRODUÇÃO}

A anemia é um problema global de saúde pública, acometendo cerca de 1,62 bilhões de pessoas no mundo, tanto nos países desenvolvidos quanto em desenvolvimento, com consequências graves para a saúde humana, bem como para o desenvolvimento social e econômico ${ }^{(1)}$.

No Brasil, o Ministério da Saúde estima que 4,8 milhões de pré-escolares sejam atingidos pela doença ${ }^{(2)}$, procedente da deficiência de ferro (DFe), cujos fatores de risco incluem: baixa ingestão alimentar, má absorção em dietas ricas em compostos fenólicos de fitato e/ou período da vida quando as necessidades são particularmente elevadas (crescimento e gravidez $)^{(1,3)}$.

A anemia por deficiência de ferro (ADFe) caracterizase pela diminuição dos níveis de hemoglobina, baixa concentração férrica no soro, fraca saturação de transferrina, e redução do hematócrito, acarretando oferta insuficiente de ferro aos tecidos e possíveis prejuízos funcionais ao organismo $4^{(3)}$.

Consequências negativas para a saúde humana têm sido reportadas, tais como repercussões no desempenho cognitivo, alterações no comportamento e crescimento de lactentes, pré-escolares e crianças em idade escolar; estado imunológico e morbidade por infecções em todas as faixas etárias; menor capacidade física e de trabalho em adolescentes e adultos ${ }^{(3,4)}$. Além disso, estudos relatam que a maior prevalência ocorre em crianças em idade préescolar $^{(3,4)}$, onde os efeitos não são susceptíveis de serem corrigidos por terapia de ferro subsequentes ${ }^{(5)}$.

Para combater e prevenir a anemia por carência de ferro, o Ministério da Saúde, através do Sistema Único de Saúde (SUS), adotou como estratégias a suplementação medicamentosa aos grupos vulneráveis através do programa nacional de suplementação de ferro (PNSF), a fortificação obrigatória das farinhas de trigo e de milho, e a educação nutricional na rede de saúde e nas escolas, incentivando aleitamento materno, alimentação complementar oportuna e saudável com diversificação da dieta, orientação alimentar nas escolas e creches $^{(6)}$

Considerando a relevância do tema para a saúde pública no Brasil, o objetivo do presente estudo foi estimar a prevalência de anemia, correlacionando o estado nutricional de crianças menores de 36 meses frequentadoras dos Centros Municipais de Educação Infantil (CMEIs) de Vitória (ES).

\section{MÉTODOS}

Estudo observacional, transversal e retrospectivo analítico, realizado de março a agosto de 2007, com 374 crianças menores de 36 meses, inscritas e que frequentavam os 43 Centros Municipais de Educação Infantil (CMEIs) de Vitória, ES, Brasil. Para a determinação do tamanho mínimo amostral, de modo que apresentasse significância estatística, utilizou-se a equação geral para tamanho de amostra em todas as populações, no qual é atribuído um desfecho com prevalência de 50\% - com um nível de significância de 5\% e intervalo de confiança (IC) de 95\%, atribuindo-se a " $p$ " o valor que resultaria no maior tamanho ${ }^{(7)}$.

Incluíram-se no estudo todas as crianças devidamente matriculadas nos CMEIs, de ambos os sexos, que à primeira avaliação estivessem na faixa etária de 6 a 36 meses, saudáveis e que portavam as autorizações dos pais ou responsáveis para participar do estudo.

Inicialmente, o responsável pela criança respondeu a um questionário estruturado contendo informações sobre as condições de nascimento e amamentação. Para obtenção dos marcadores socioeconômicos, utilizaram-se os dados da ficha de matrícula da criança: grau de escolaridade da mãe e a renda familiar em salários mínimos (SM), transformada em renda mensal per capta.

A avaliação do estado nutricional se deu mediante as variáveis: peso e comprimento/estatura. Utilizou-se balança eletrônica portátil da marca Plena ${ }^{\mathbb{B}}$ para aferição do peso, e para a mensuração do comprimento/estatura foram usados infantômetro (para crianças menores de 2 anos de idade) e estadiômetro (para crianças maiores de 2 anos de idade), ambos da marca Alturaexata ${ }^{\circledR}$.

As crianças estavam despidas ou usando roupas íntimas leves no momento da aferição do peso. Crianças de até 2 anos de idade permaneceram posicionadas em decúbito dorsal e, a partir dessa idade, na posição ereta, para a mensuração do comprimento/estatura, tomando-se as devidas precauções para que a coluna e as pernas permanecessem retificadas ${ }^{(8)}$.

Realizou-se a avaliação do estado nutricional mediante os índices peso para idade $(\mathrm{P} / \mathrm{I})$, peso para estatura $(\mathrm{P} / \mathrm{E}) \mathrm{e}$ estatura para idade (E/I). Adotou-se o limite de corte de - 2 desvios padrões (DP) para caracterização de déficit de P/I, $\mathrm{P} / \mathrm{E}$ e E/I, de acordo com os escores $\mathrm{Z}$, e para diagnóstico de sobrepeso/obesidade, nos índices P/I e P/E +2 DP, conforme recomendação da $\mathrm{OMS}^{(9,10)}$.

Os familiares das crianças receberam instruções quanto à realização do exame bioquímico, sendo encaminhados ao Laboratório de Análises Clínicas "Henrique Tommasi", que financiou as dosagens bioquímicas de $\mathrm{Hb}$, FS e FeS, empregadas para o diagnóstico de anemia, sendo este dado por $\mathrm{Hb}<11 \mathrm{~g} / \mathrm{dL}$, depleção de ferro por FS $<12 \mu \mathrm{g} / \mathrm{l}$ e FeS $<$ $50 \mu \mathrm{g} / \mathrm{dL}{ }^{(11)}$. Para definição dos graus de anemia, adotaramse as seguintes categorias: anemia leve ( $\mathrm{Hb}$ entre 9,0 e $11,0 \mathrm{~g} / \mathrm{dL}$ ), anemia moderada ( $\mathrm{Hb}$ entre 7,0 e $<9,0 \mathrm{~g} / \mathrm{dL}$ ) e anemia grave $(\mathrm{Hb}<7,0 \mathrm{~g} / \mathrm{dL})^{(12)}$.

Para a análise estatística utilizou-se o SPSS (Statistical Package for Social Sciences for Windows versão 10.0). A 
relação entre as diversas variáveis independentes e cada uma das variáveis dependentes, foi realizada mediante o teste do qui-quadrado e teste exato de Fisher.

Cálculos demedidas detendência centralevariabilidades para análise estatística descritiva (prevalência, mediana, média e desvio-padrão) foram empregados e consideraramse estatisticamente significantes $p<0,05$ e intervalo de confiança (IC) de 95\%.

O presente trabalho recebeu aprovação do Comitê de Ética em Pesquisa da Faculdade Salesiana de Vitória sob o n ${ }^{\circ} 01 / 2006$, bem como pelas autoridades municipais. O envolvimento de cada família foi formalizado mediante a assinatura do "Termo de Consentimento Livre e Esclarecido (TCLE)" após o recebimento de informações pertinentes ao projeto, tais como finalidade, benefícios para a criança e a comunidade em geral, e risco mínimo para a criança decorrente dos procedimentos adotados. Por motivos éticos, todas as crianças com diagnósticos de anemia foram encaminhadas para a unidade de saúde de referência para acompanhamento.

\section{RESULTADOS}

A amostra foi constituída por 374 crianças, composta de $50,8 \%(n=190)$ do sexo feminino. Na distribuição por faixa etária, houve maior prevalência de crianças com idade entre 24 e 36 meses, sendo observada alta prevalência de aleitamento materno em algum momento de suas vidas, apesar de somente $17,1 \%(n=64)$ ter mamado exclusivamente até o sexto mês de vida. Com relação ao estado nutricional nos índices P/I, E/I, P/E, a maioria das crianças encontravam-se eutróficas (Tabela I).

Nos índices $\mathrm{P} / \mathrm{I}$ e $\mathrm{P} / \mathrm{E}, 11,8 \%(\mathrm{n}=44)$ das crianças apresentaram baixo peso, enquanto $23,5 \% \quad(n=88)$ apresentaram peso elevado/I e $22,7 \% \quad(n=85)$ peso elevado/E. Em relação ao baixo P/I, foram encontradas prevalências semelhantes em ambos os sexos. As crianças do sexo feminino apresentaram maior prevalência $(8,0 \%)$ $(\mathrm{n}=15)$ de peso elevado, no entanto o índice $\mathrm{P} / \mathrm{E}$, apresentou $2,8 \%(\mathrm{n}=5)$ crianças do sexo masculino com baixo peso. $\mathrm{O}$ déficit de $\mathrm{E} / \mathrm{I}$ foi observado em $14,2 \%(\mathrm{n}=53)$ das crianças, sendo a maior prevalência observada no sexo masculino. Ainda na Tabela I, é possível observar que $8,8 \%(\mathrm{n}=33)$ das mães eram adolescentes ao nascimento da criança.

As dosagens de $\mathrm{Hb}, \mathrm{FS}$ e $\mathrm{FeS}$ foram realizadas em $46,5 \%(\mathrm{n}=174)$ da amostra, sendo $50 \%(\mathrm{n}=87)$ do sexo masculino. A caracterização das variáveis hematológicas da amostra está apresentada na Tabela II.

Observou-se anemia $(\mathrm{Hb}<11,0 \mathrm{~g} / \mathrm{dL})$ em 10,9\% ( $\mathrm{n}=19)$ das crianças, sendo a maior prevalência no sexo masculino (12 e 6,9\%). Não foi observada anemia grave nesta amostra e níveis inadequados de FeS e FS estiveram presentes em
$27,6 \%(n=48)$ e $7,5 \%(n=13)$ das crianças, respectivamente. (Tabela III)

O estado nutricional infantil não mostrou associação estatisticamente significante com a anemia (Tabela IV).

Tabela I - Distribuição das variáveis biológicas, nutricionais e socioeconômicas de crianças menores de 36 meses de creches públicas. Vitória-ES, 2007.

\begin{tabular}{|c|c|c|}
\hline Variáveis & $\mathbf{n}$ & $\%$ \\
\hline \multicolumn{3}{|l|}{ Sexo } \\
\hline Masculino & 184 & $49,2 \%$ \\
\hline Feminino & 190 & $50,8 \%$ \\
\hline \multicolumn{3}{|l|}{ Faixa etária } \\
\hline$<24$ meses & 112 & $30,0 \%$ \\
\hline $24-36$ meses & 262 & $70,0 \%$ \\
\hline \multicolumn{3}{|c|}{ Peso ao Nascer (em gramas) } \\
\hline$<2500$ & 15 & $4,0 \%$ \\
\hline $2500-4000$ & 328 & $87,7 \%$ \\
\hline$>4000$ & 31 & $8,3 \%$ \\
\hline \multicolumn{3}{|c|}{ Aleitamento Materno Exclusivo* } \\
\hline$<6$ meses & 179 & $47,9 \%$ \\
\hline 6 - 24 meses & 184 & $49,2 \%$ \\
\hline Ausente & 11 & $2,9 \%$ \\
\hline \multicolumn{3}{|c|}{ Alimentação complementar } \\
\hline$\leq 6$ meses & 310 & $82,9 \%$ \\
\hline$>6$ meses & 64 & $17,1 \%$ \\
\hline \multicolumn{3}{|l|}{ Estado Nutricional } \\
\hline \multicolumn{3}{|l|}{$\mathrm{P} / \mathrm{I}$} \\
\hline Baixo peso & 44 & $11,8 \%$ \\
\hline Eutrófico & 242 & $64,7 \%$ \\
\hline Peso Elevado & 88 & $23,5 \%$ \\
\hline \multicolumn{3}{|l|}{$\mathrm{E} / \mathrm{I}$} \\
\hline Eutrófico & 321 & $85,8 \%$ \\
\hline Baixa estatura & 53 & $14,2 \%$ \\
\hline \multicolumn{3}{|l|}{$\mathrm{P} / \mathrm{E}$} \\
\hline Baixo peso & 44 & $11,8 \%$ \\
\hline Eutrófico & 245 & $65,5 \%$ \\
\hline Peso Elevado & 85 & $22,7 \%$ \\
\hline \multicolumn{3}{|l|}{ Renda per capta } \\
\hline$<0,5 \mathrm{SM}$ & 210 & $56,1 \%$ \\
\hline 0,5 a $1 \mathrm{SM}$ & 102 & $27,3 \%$ \\
\hline$>1 \mathrm{SM}$ & 62 & $16,6 \%$ \\
\hline \multicolumn{3}{|c|}{ Idade materna ao nascimento da criança } \\
\hline$<18$ anos & 33 & $8,8 \%$ \\
\hline 18 a 35 anos & 310 & $82,9 \%$ \\
\hline$>35$ anos & 31 & $8,3 \%$ \\
\hline \multicolumn{3}{|l|}{ Escolaridade materna } \\
\hline$<8$ anos & 67 & $17,9 \%$ \\
\hline 8 a 11 anos & 261 & $69,8 \%$ \\
\hline$>11$ anos de estudo & 46 & $12,3 \%$ \\
\hline Total & 374 & $100,0 \%$ \\
\hline
\end{tabular}

*ausência de qualquer alimento diferente do leite materno P/I: Peso para Idade; E/I: Estatura para Idade; P/E: Peso para Estatura; SM: Salário Mínimo 
Tabela II - Distribuição de variáveis hematológicas de crianças menores de 36 meses de creches públicas. Vitória-ES, 2007.

\begin{tabular}{lccccc}
\hline Variáveis & Mínimo & Máximo & Mediana & Média & Desvio-padrão \\
\hline Hemoglobina $(\mathrm{g} / \mathrm{dL})$ & 7,20 & 14,61 & 12,11 & 12,11 & 1,04 \\
Ferro Sérico $(\mu \mathrm{g} / \mathrm{dL})$ & 10,00 & 343,00 & 66,00 & 73,61 & 40,44 \\
Ferritina Sérica $(\mu \mathrm{g} / \mathrm{L})$ & 1,50 & 167,00 & 31,05 & 37,96 & 27,19 \\
\hline
\end{tabular}

Tabela III - Prevalência de anemia ferropriva por variável hematológica de crianças menores de 36 meses de creches públicas. Vitória-ES, 2007.

\begin{tabular}{lcc}
\hline Variáveis & n & \% \\
\hline Hemoglobina & 19 & 10,9 \\
Anemia & 155 & 89,1 \\
Normal & & 27,6 \\
Ferro Sérico & 48 & 72,4 \\
Anemia & 126 & 7,5 \\
Normal & & 92,5 \\
Ferritina Sérica & 13 & 100 \\
Anemia & 161 & \\
Normal & 174 & \\
Total & & \\
\hline
\end{tabular}

Tabela IV - Associação entre o estado nutricional e níveis de anemia ferropriva em crianças menores de 36 meses de creches públicas.Vitória-ES, 2007.

\begin{tabular}{|c|c|c|c|c|c|c|c|}
\hline \multirow{3}{*}{ Variáveis } & \multicolumn{6}{|c|}{ Anemia } & \multirow{3}{*}{$p$} \\
\hline & \multicolumn{2}{|c|}{ Ausente } & \multicolumn{2}{|c|}{ Leve } & \multicolumn{2}{|c|}{ Moderada } & \\
\hline & $\mathbf{n}$ & $\%$ & $\mathbf{n}$ & $\%$ & $\mathbf{n}$ & $\%$ & \\
\hline \multicolumn{8}{|l|}{$\mathrm{P} / \mathrm{I}$} \\
\hline Baixo peso & 4 & 2,6 & 0 & 0,0 & 0 & 0,0 & \multirow{3}{*}{0,812} \\
\hline Eutrófico & 143 & 92.3 & 17 & 100,0 & 2 & 100,0 & \\
\hline $\mathrm{P} / \mathrm{E}^{\text {Peso Elevado }}$ & 8 & 5,2 & 0 & 0,0 & 0 & 0,0 & \\
\hline Baixo peso & 6 & 3,9 & 0 & 0,0 & 0 & 0,0 & \multirow{3}{*}{0,078} \\
\hline Eutrófico & 139 & 89,7 & 17 & 100,0 & 1 & 50,0 & \\
\hline \multicolumn{7}{|l|}{$\mathrm{E} / \mathrm{I}$} & \\
\hline Eutrófico & 152 & 98,1 & 16 & 94,1 & 2 & 100,0 & \multirow{2}{*}{0,574} \\
\hline Baixa E/I & 3 & 1,9 & 1 & 5,9 & 0 & 0,0 & \\
\hline Total & 155 & 100,0 & 17 & 100,0 & 2 & 100,0 & - \\
\hline
\end{tabular}

P/I: Peso para Idade; E/I: Estatura para Idade; P/E: Peso para Estatura

\section{DISCUSSÃO}

A prevalência de anemia $(\mathrm{Hb}<11,0 \mathrm{~g} / \mathrm{dL})$ observada no presente estudo foi de $10,9 \%$ o que caracteriza um problema de saúde pública leve ${ }^{(12)}$. Destaca-se que essa prevalência demonstra uma tendência ascendente, visto que foi superior à encontrada em estudo semelhante conduzido em Vitória, ES no ano de $2004^{(13)}$. No entanto, maior prevalência de anemia foi constatada em estudos nacionais localizados, cujos valores oscilam de 25,0 a $63,0 \%$ entre menores de 3 anos de idade ${ }^{(14-16)}$.

A variação temporal na prevalência de anemia e fatores associados foi estudada em crianças de 6 a 59 meses, período de 1997 a 2006 no estado de Pernambuco, cujos dados revelaram um panorama otimista, visto que um decréscimo de 19,3\% na ocorrência desta deficiência 
nutricional foi detectada - declínio de 40,9\% para 33,0\%16 cuja explicação pode estar associada às políticas públicas para o controle da anemia ${ }^{(17)}$ implantadas no Brasil.

A Pesquisa Nacional de Demografia e Saúde da Criança e da Mulher ${ }^{(18)}$, realizada com 3455 crianças menores de cinco anos, observou que a menor prevalência de anemia ocorreu na região Norte $(10,4 \%)$, valor este que corrobora ao do presente estudo. Já a região Nordeste diagnosticou $25,5 \%$ das crianças como anêmicas. Resultados superiores ao presente estudo foram encontrados nos estados da Paraíba $^{(19)}(25,1 \%)$, Minas Gerais ${ }^{(20)}(30,6 \%)$, Acre ${ }^{(15)}$ $(29,2 \%)$, Pernambuco ${ }^{(21)}(55,6 \%)$ e São Paulo ${ }^{(22)}(43,6 \%)$, para faixa etária semelhante.

Há uma concordância entre autores de que a idade da criança seja um dos fatores mais predisponentes na gênese da anemia ${ }^{(13,19,23)}$, principalmente na faixa etária de 6 a 24 meses $^{(23,24)}$, devido ao curto período de aleitamento materno exclusivo, baixa ingestão de alimentos ricos em ferro, crescimento acelerado e introdução precoce de leite de vaca, cuja quantidade de ferro é pequena e de baixa biodisponibilidade ${ }^{(25)}$. Nota-se que, no presente estudo, a maior parte das crianças $(82,9 \%)$ iniciou alimentação complementar em idade inferior a seis meses, sendo este considerado fator preditor de risco em potencial para a prevalência de anemia ferropriva em pré-escolares ${ }^{(23,25,26)}$.

A distribuição de anemia segundo o sexo, na presente pesquisa, apresentou caráter heterogêneo, cujas prevalências mais elevadas $(6,9 \%)$ ocorreram no sexo masculino em relação ao sexo feminino $(4,0 \%)$, semelhante ao resultado realizado com pré-escolares na Paraíba ${ }^{(19)}$, que observou níveis mais baixos de hemoglobina no sexo masculino, o que também foi constatado em estudos regionais ${ }^{(15,27)}$. A maior prevalência de anemia no sexo masculino pode ser explicada pela maior velocidade de crescimento apresentada pelos meninos, acarretando maior necessidade de ferro pelo organismo, não suprida pela $\operatorname{dieta}^{(28)}$. Em contraste, demonstra-se que, em crianças, não existe diferença na prevalência de anemia por sexo ${ }^{(29,30)}$.

Os riscos nutricionais diagnosticados no presente estudo, a saber, baixo peso/idade; baixa estatura/idade e baixo peso/estatura têm prevalências menores do que as ocorrências de anemia, corroborando com o estudo realizado em CMEIs do município de Cascavel $(\mathrm{PR})^{(31)}$. $\mathrm{O}$ déficit de estatura em relação à idade, foi observado em $2,3 \%$ da amostra da atual pesquisa, resultado próximo ao encontrado em estudo conduzido no Rio Grande do Sul, que foi de $3,7 \%{ }^{(32)}$

No que tange ao parâmetro P/I, 2,6\% das crianças investigadas no presente estudo apresentaram baixo peso, sendo que, destas, nenhuma obteve associação com o diagnóstico de anemia. E, em contrapartida, todas as crianças anêmicas $(10,9 \%)$ da atual pesquisa tiveram diagnóstico nutricional de eutrofia. Quanto ao índice $\mathrm{P} / \mathrm{E}$, $3,9 \%$ das crianças com diagnóstico de baixo peso, nenhuma apresentou anemia, enquanto $6,3 \%$ das que estavam com peso elevado, $0,6 \%$ apresentou anemia moderada $(\mathrm{Hb}<9,0$ e $>7,0 \mathrm{~g} / \mathrm{dl}$ ). O diagnóstico nutricional de baixo peso no geral não apresentou associação com anemia, corroborando com outros estudos ${ }^{(20,33,34)}$. Isso demonstra que a carência de ferro possa ser oriunda de uma alimentação com baixa disponibilidade desse nutriente, nem sempre acompanhado de baixa ingestão protéico-calórica ${ }^{(26,35)}$. É importante ressaltar que, no presente estudo, as crianças apresentaram maiores prevalências de sobrepeso/obesidade do que baixo peso nos índice $\mathrm{P} / \mathrm{I}$ e $\mathrm{P} / \mathrm{E}$, reforçando a transição nutricional nesta faixa etária, cujos cuidados com a alimentação complementar deveriam ser priorizados.

Dentre os fatores de risco que integram a anemia em crianças menores de 5 anos de idade, observa-se uma associação significativa da anemia com a idade materna ${ }^{(25)}$, sendo maior a prevalência da doença em filhos de mães adolescentes, possivelmente devido a maior probabilidade que as mães adolescentes têm de conceber filhos com baixo peso, fator diretamente ligado a menor reserva de ferro. Entretanto, no presente estudo a maior prevalência de anemia ocorreu em filhos de mães com idade entre $18 \mathrm{e}$ 35 anos e que nasceram com peso adequado, semelhante ao observado por outros autores ${ }^{(36,37)}$.

A escolaridade dos pais pode ser também considerada um fator socioeconômico importante na determinação da anemia $^{(16)}$, tendo em vista que a maior escolaridade repercute numa maior chance de emprego e, consequentemente, de renda, que, por sua vez, condiciona um melhor acesso aos alimentos ${ }^{(23)}$. Além disso, o maior nível de conhecimento formal materno parece influenciar nas práticas relacionadas aos cuidados com a criança ${ }^{(23)}$. Ao se estudar subgrupos de maior risco para anemia em crianças de creches municipais de Belo Horizonte, observou-se maior prevalência de anemia em filhos de pais com menor escolaridade ${ }^{(30)}$. No presente estudo, somente a escolaridade materna foi considerada e não se mostrou associada à prevalência de anemia. Resultados semelhantes também foram encontrados em outros estudos ${ }^{(29,32)}$.

Em São Paulo, estudo realizado em creches públicas e filantrópicas concluiu que a renda familiar per capita foi uma das variáveis indicadora dos processos estruturais da sociedade que se associou de forma estatisticamente significante com anemia, cujas crianças de família com renda per capita de até $0,5 \mathrm{SM}$ tiveram um risco adicional de $56 \%$ de apresentar anemia ${ }^{(22)}$. Apesar de não ter sido associada à anemia, observou-se no presente estudo que 
quanto menor a renda, maior foi a prevalência de anemia, constatação essa também relatada em outros estudos ${ }^{(14,30,38)}$.

Ainda que a concentração de $\mathrm{Hb}$ seja o indicador mais confiável da anemia em nível de população ${ }^{(1)}$, não é específica para deficiência de ferro ${ }^{(11)}$. O nível de FS é o teste bioquímico mais específico que se correlaciona com os estoques de ferro corporal total. Um baixo nível de FS reflete baixas reservas de ferro e, portanto, é condição prévia para a DFe, na ausência de infecção ${ }^{(11)}$. Não obstante, as reservas de ferro, quando exauridas, qualquer declínio adicional a nível corporal é acompanhado por uma redução na concentração do ferro sérico ${ }^{(12)}$, o que torna importante avaliar, também, esse parâmetro bioquímico no diagnóstico de DFe.

Segundo a OMS, quando a prevalência de anemia da população é de até $40 \%$, a deficiência de ferro é cerca de 2,5 vezes maior ${ }^{(11)}$. Subsidiando tais estimativas, a prevalência de concentrações inadequados de $\mathrm{FeS}$ na população investigada da presente pesquisa foi de $27,6 \%$. Resultado semelhante foi constatado em creches da rede pública de Cascavel (Paraná), onde se observou prevalência de anemia em $29,7 \%$ da população avaliada, em contraste aos baixos níveis de FeS em 77,3\% das crianças $^{(31)}$.

Quanto aos níveis séricos de FS, o presente estudo encontrou prevalência inferior $(7,5 \%)$ em relação à anemia, no entanto, outros estudos têm relatado prevalências superiores $^{(27,39)}$. No Rio Grande do $\mathrm{Sul}^{(27)}$, a deficiência de ferro avaliada pela FS foi constatada em 91,0 e 89,3\% da população do sexo masculino e feminino, respectivamente, em crianças de 12 a 16 meses. No entanto, na faixa etária de 3 a 4 meses tal deficiência foi diagnosticada em 19,5\% do sexo masculino e $11,6 \%$ no sexo feminino.

Embora a deficiência de ferro seja provavelmente a causa mais comum de anemia, há outras causas como infecções agudas e crônicas que causam a inflamação; outras deficiências de micronutrientes, especialmente de ácido fólico, vitamina $B_{12}$ e vitamina $A$; e características herdadas geneticamente, como talassemia ${ }^{(24)}$, que não foram avaliadas no presente estudo.

A ausência de informações relevantes, tais como o uso de suplementação de ferro, avaliação do consumo alimentar das crianças e presença de infecção podem ser consideradas limitações do estudo, visto que esses fatores têm relação direta com a prevalência de anemia ferropriva.

Em síntese, a prevalência de anemia (10,9\%), avaliada pela $\mathrm{Hb}$, caracterizou um problema de saúde pública leve, no entanto, quando tal carência nutricional é avaliada pelo FeS detectou-se uma amplitude maior do problema entre as crianças dos CMEI's de Vitória(ES). O estado nutricional não mostrou associação a tal distúrbio, mas o acompanhamento nutricional de crianças nesta faixa etária se faz necessário devido à ocorrência de riscos nutricionais diagnosticados, em especial, baixo peso $(11,8 \%)$, baixa estatura $(14,2 \%)$, e em contraponto, o peso elevado observado em quase $23,0 \%$ da amostra estudada. Identificou-se também a alta ocorrência de interrupção do aleitamento materno antes dos seis meses de vida, e introdução precoce da alimentação complementar, praticas inadequadas quanto à prevenção de anemia ferropriva.

Diante do exposto, sugere-se que práticas mais drásticas e imediatas que visem a educação nutricional aos educadores e mães de crianças que frequentam creches devem ser adotadas, visando melhor qualidade de vida de crianças, principalmente aquelas com idade inferior a 5 anos. Considerando-se a relevância da anemia ferropriva na promoção da saúde, sugerem-se aos gestores das políticas públicas, atenção diferenciada a este distúrbio, no intuito de detectar as falhas das políticas propostas, através de ações de vigilância específica para a anemia, procurando soluções mais eficazes tanto em nível de prevenção, tratamento e acompanhamento desse agravo à saúde.

\section{CONCLUSÃO}

Apesar de implantadas medidas de saúde pública para a prevenção e combate de anemia, como a suplementação profilática de sulfato ferroso e fortificação dos alimentos, observa-se que a prevalência de anemia nos lactentes e pré-escolares de Vitória-ES (10,9\%) ainda caracteriza um problema de saúde pública, não estando este distúrbio associado ao estado nutricional da criança.

\section{AGRADECIMENTOS}

Ao laboratório Tommasi pela realização dos exames bioquímicos.

\section{REFERÊNCIAS}

1. Benoist Bd, McLean E, Egll I, Cogswell M. Worldwide prevalence of anaemia 1993-2005: WHO global database on anaemia. Geneva: WHO; 2008.

2. Ministério da Saúde (BR), Coordenação Geral da Política de Alimentação e Nutrição. Oficina de Trabalho "Carências Nutricionais: Desafio para a Saúde Pública”. Brasília: Ministério da Saúde; 2004.

3. Abbaspour N, Hurrell R, Kelishadi R. Review on iron and its importance for human health $\mathrm{J}$ Res Med Sci. 2014;19(2):164-74.

4. Miller JL. Iron deficiency anemia: a common and curable disease. Cold Spring Harbor Perspectives Medicine. 2013;3(7):1-13. 
5. Thompson J, Biggs BA, Pasricha SR. Effects of daily iron supplementation in 2-to 5-year-old children: systematic review and meta-analysis. Pediatrics. 2013;131(4):739-53.

6. Ministério da Saúde (BR), Secretaria de Atenção à Saúde, Departamento de Atenção Básica. Manual operacional do Programa Nacional de Suplementação de Ferro. Brasília: Ministério da Saúde; 2005. (Série A. Normas e Manuais Técnicos).

7. Rea LM, Parker RA. Metodologia de pesquisa: do planejamento a execução. São Paulo: Cengage Learning; 2002.

8. Alves CRL, Alvim CG, Junqueira HS, Goulart L, Dias LS, Magalhães MEN, et al. Atenção à saúde da criança. Belo Horizionte: Secretaria de Estado de Saúde de Minas Gerais; 2005.

9. Kuczmarski RJ, Ogden CL, Guo SS, Grummer-Strawn LM, Flegal KM, Mei Z, et al. 2000 CDC Growth Charts for the United States: methods and development. Vital Health Stat 11. 2002;(246):1-190.

10. World Health Organization - WHO. Physical status: the use and interpretation of anthropometry. Geneva: WHO; 1995. (WHO technical report series, 854).

11. World Health Organization - WHO. Assessing the iron status of populations: report of a Joint World Health Organization. Geneva: WHO; 2005.

12. World Health Organization - WHO. Iron deficiency anaemia: assessment, prevention and control: a guide for programme managers. Geneva: WHO; 2001.

13. Almeida APC, Zandonade E, Abrantes MM, Alves J. Deficiência de ferro e anemia em crianças de Vitória, ES. Pediatria (São Paulo). 2004;26(3):140-50.

14. Miglioli TC, Brito AM, Lira PIC, Figueroa JN. Anemia no binômio mãe-filho no Estado de Pernambuco, Brasil Mother-child anemia in the State of Pernambuco, Brazil. Cad Saúde Pública. 2010;26(9):1807-20.

15. Castro TG, Silva-Nunes M, Conde WL, Muniz PT, Cardoso MA. Anemia e deficiência de ferro em pré-escolares da Amazônia Ocidental brasileira: prevalência e fatores associados. Cad Saúde Pública. 2011;27(1):131-42.

16. Leal LP, Osório MM. Fatores associados à ocorrência de anemia em crianças menores de seis anos: uma revisão sistemática dos estudos populacionais. Rev Bras Saúde Matern Infant. 2010;10(4):417-39.

17. Szarfarc SC. Políticas públicas para o controle da anemia ferropriva: revisão. Rev Bras Hematol Hemoter. 2010;32(Supl 2):2-8.
18. Ministério da Saúde (BR). Pesquisa Nacional de Demografia e Saúde da Criança e da Mulher-PNDS 2006: dimensões do processo reprodutivo e da saúde da criança. Brasília: Ministério da Saúde; 2009.

19. Gondim SSR, Diniz AS, Souto RA, Bezerra RGS, Albuquerque EC, Paiva AA. Magnitude, tendência temporal e fatores associados à anemia em crianças do Estado da Paraíba. Rev Saúde Pública. 2012;46(4):64956.

20. Castro SC, Ribeiro III RCL, LamounierIV JA, Pedron VFA. Efetividade superior do esquema diário de suplementação de ferro em lactentes. Rev Saúde Pública. 2010;44(2):230-9.

21. Vieira ACF, Diniz AS, Cabral PC, Oliveira RS, Lóla MM, Silva SM, et al. Nutritional assessment of iron status and anemia in children under 5 years old at public daycare centers. J Pediatr. 2007;83(4):370-6.

22. Konstantyner T, Taddei JAA, Oliveira MN, Palma D, Colugnati FA. Isolated and combined risks for anemia in children attending the nurseries of daycare centers. J Pediatr. 2009;85(3):209-16.

23. Osório MM. Fatores determinantes da anemia em crianças. J Pediatr. 2002;78(4):269-78.

24. Jordão RE, Bernardi JLD, Barros Filho AdA. Prevalência de anemia ferropriva no Brasil: uma revisão sistemática. Rev Paul Pediatr. 2009;27(1):90-8.

25. Oliveira MA, Osório MM. Consumo de leite de vaca e anemia ferropriva na infância. J Pediatr. 2005;81(5):361-7.

26. Caetano MC, Ortiz T, Silva S, Souza F, Sarni ROS. Alimentação complementar: práticas inadequadas em lactentes. Arch Pediatr Urug. 2012;83(3):226-32.

27. Bortolini GA, Vitolo MR. Relationship between iron deficiency and anemia in children younger than 4 years. J Pediatr. 2010;86(6):488-92.

28. Wieringa FT, Berger J, Dijkhuizen MA, Hidayat A, Ninh NX, Utomo B, et al. Sex differences in prevalence of anaemia and iron deficiency in infancy in a large multi-country trial in South-East Asia. Br J Nutr. 2007;98(05):1070-6.

29. Oliveira TSCd, Silva MC, Santos JN, Rocha DS, Alves CRL, Capanema FD, et al. Anemia among preschool children-a public health problem in Belo Horizonte, Brazil. Ciênc Saúde Coletiva. 2014;19(1):59-66.

30. Rocha DS, Capanema FD, Pereira Netto M, Franceschini SdCC, Lamounier JA. Prevalence and risk factors of anemia in children attending daycare 
centers in Belo Horizonte-MG. Rev Bras Epidemiol. 2012;15(3):675-84.

31. Rodrigues VC, Mendes BD, Gozzi A, Sandrini F, Santana RG, Matioli G. Deficiência de ferro, prevalência de anemia e fatores associados em crianças de creches públicas do oeste do Paraná, Brasil. Rev Nutr. 2011;24(3):407-20.

32. Scherer F, Beneduzi VL. Perfil nutricional e prevalência de anemia ferropriva em crianças. Conscientiae Saúde. 2011;10(3):433-40

33. Oliveira MN, Martorell R, Nguyen P. Risk factors associated with hemoglobin levels and nutritional status among Brazilian children attending daycare centers in Sao Paulo City, Brazil. Arch Latinoam Nutr. 2010;60(1):23-9.

34. Pedraza DF, Rocha ACD, Sousa CPC. Crescimento e deficiências de micronutrientes: perfil das crianças assistidas no núcleo de creches do governo da Paraíba, Brasil. Ciênc Saúde Coletiva. 2013;18(11):3379-90.

35. Goulart RMM, Banduk MLS, Taddei JAdAC. A review of nutrition actions and the role of dieticians in daycares. Rev Nutr. 2010;23(4):655-65.

36. Silveira SV, Albuquerque LC, Rocha EJM, Vale Martins MC. Fatores de risco associados à anemia ferropriva em crianças de 12 a 36 meses de creches públicas em Fortaleza. Rev Pediatr. 2008;9(2):70-6.
37. Hadler M, Juliano Y, Sigulem DM. Anemia do lactente: etiologia e prevalência. J Pediatr. 2002;78(4):321-6.

38. Oliveira MAA, Osório MM, Raposo MCF. Concentração de hemoglobina e anemia em crianças no Estado de Pernambuco, Brasil: fatores sócioeconômicos e de consumo alimentar associados. Cad Saúde Pública. 2006;22(10):2169-78.

39. Almeida C, Ricco RG, Ciampo L, Souza AM, Pinho AP, Oliveira J. Fatores associados a anemia por deficiência de ferro em crianças pré-escolares brasileiras. J Pediatr. 2004;80(3):229-34.

\section{Endereço para correspondência:}

Márcia Mara Correa

Hospital Universitário Cassiano Antônio Moraes

(HUCAM)

Universidade Federal do Espírito Santo (UFES)

Av. Marechal Campos, 1355

Bairro: Santos Dumont

CEP: 29040091 - Vitória - ES - Brasil

E-mail: marciamara@uol.com.br 